\title{
El Coll del Moro (Gandesa, Tarragona) y su contexto territorial: formación y desarrollo de un asentamiento urbano protohistórico*
}

\author{
Coll del Moro (Gandesa, Tarragona) and its territorial context: formation and \\ development of a protohistoric urban settlement
}

\author{
Rafel Jornet Niella ${ }^{a}$, M. Carme Belarte ${ }^{b}$, Joan Sanmartía, David Asensio ${ }^{a}$, Jordi Morer ${ }^{a}$ \\ y Jaume Noguera ${ }^{a}$
}

\section{RESUMEN}

Los trabajos realizados entre 2014 y 2019 en este importante núcleo, situado estratégicamente entre las cuencas de los ríos Ebro y Matarraña, han combinado la excavación en extensión, la prospección intensiva del asentamiento y de su entorno inmediato, los análisis interdisciplinares y la revisión de las intervenciones anteriores. Los resultados permiten reinterpretar la evolución del asentamiento entre el Primer Hierro y el Alto Imperio. Su extensión inicial debió de ser reducida, con una función limitada al control del territorio y ejercida desde una gran torre, mientras que en el siglo III a. C. alcanzó su máxima extensión ( 3 ha) y se erigió una gran mansión aristocrática. Esta evolución refleja el proceso de estratificación y urbanización de la sociedad ibérica de la zona, truncado por la conquista romana. En época romano-republicana se construyó un edificio fortificado que recuperó la función de punto de control, para pasar a ser ocupado esporádicamente en el Alto Imperio. disciplinary analysis, and a review of previous works. The results throw new light on the evolution of the settlement between the Early Iron Age and the Early Empire. Its initial extension must have been reduced, and aimed to control the territory from a large tower, while in the $3 r d$ century $B C$ the settlement reached its maximum surface ( $3 \mathrm{ha}$ ) and a large aristocratic mansion was erected. This evolution reflects the stratification and urbanisation processes of the Iberian society in the area, which would be truncated by the Roman conquest. In the Roman Republican era, a fortified building was built that recovered the site's function as a control point; this would be sporadically occupied during the early Roman Empire.

Palabras clave: Protohistoria de la península ibérica; Romanización; Hábitat; Cultura ibérica; Urbanización; Cambio sociocultural.

Key words: Protohistory of the Iberian peninsula; Romanization; Habitat; Iberian culture; Urbanization; Socio-cultural change.

\section{INTRODUCCIÓN}

El Coll del Moro está constituido por una gran necrópolis tumular del Bronce Final-Primer Hierro,

\footnotetext{
${ }^{*}$ Las intervenciones han sido financiadas por el Ministerio de Ciencia, Innovación y Universidades, el Departamento de Cultura de la Generalitat de Catalunya y el Ayuntamiento de Gandesa: proyectos "Caracterización de los asentamientos urbanos en la costa de la Iberia septentrional (siglos VI-III a. C.)" (HAR2015-67946-C2-1-P y HAR2015-67946-C2-2-P), "El primer mil·lenni aC als territoris del curs inferior de 1'Ebre: la formació, desenvolupament i dissolució de la cultura ibérica" (CULT 2014/100756) y "La formació, desenvolupament i dissolució de la cultura ibérica al curs inferior de l'Ebre (s. IX-I aC)"'(CLT009/18/00027).

a Universidad de Barcelona, Dpto. de Historia y Arqueología. C/ Montalegre 6-8. Barcelona 08001. Correos e.: RJN rafeljornet@ub.edu https://orcid.org/0000-0002-7860-909X; JSG sanmarti@ub.edu https://orcid.org/0000-0002-6635-9249; DAV davidasensio@ub.edu https://orcid.org/0000-0003-3957-8435; JMLL jmorerdellorens@gmail.com https://orcid.org/0000-0003-4199-4358; JNG noguera@ub.edu https://orcid.org/0000-0001-5698-3606

b Institució Catalana de Recerca i Estudis Avançats (ICREA). Pg. Lluís Companys 22. 08010 Barcelona e Institut Català d'Arqueologia Clàssica (ICAC). Pl. Rovellat 2/n. 43003 Tarragona. Correo e.: cbelarte@icac.cat https://orcid.org/0000-0002-2293-0482

Recibido 12-XII-2019; aceptado 24-II-2020.
}

Copyright: (C) 2020 CSIC. Este es un artículo de acceso abierto distribuido bajo los términos de la licencia de uso y distribución "Creative Commons Reconocimiento 4.0 Internacional” (CC BY 4.0) 
que perduró residualmente en época ibérica, y por un asentamiento fechable a partir del siglo VII a. C., con una importante fase de ocupación durante el período ibérico, otra, también notable, tardorepublicana, y una última de época imperial, mucho más tenue. Está situado en el término municipal de Gandesa, en la comarca de la Terra Alta (Tarragona), sobre una collada, a unos $480 \mathrm{~m} \mathrm{~s}$. n. m., que se extiende entre las sierras de Botja y de la Fatarella. Ambas constituyen el extremo septentrional del Sistema Ibérico y separan las cuencas del Algars, al noroeste, y del Canaleta, al sureste, ríos tributarios del Ebro (Fig. 1A). Esta vía de comunicación natural entre el curso inferior del Ebro y el Bajo Aragón es aprovechada por la carretera N-420, que discurre por la parte superior de la vertiente meridional de la collada, y que ha seccionado el conjunto arqueológico (Fig. 1B), localizado a $6 \mathrm{~km}$ al oeste de Gandesa. Desde el mismo se divisa un amplio panorama, desde Corbera d'Ebre al este hasta Horta de Sant Joan al oeste, y, en particular, el llano de Bot, situado a los pies de la collada. Aún más al sur se divisan las sierras de Bot, Pàndols y Cavalls, al este de las cuales discurre el tramo inferior del Ebro. Esta ubicación es privilegiada por el dominio visual sobre el territorio, el control sobre las comunicaciones y también por la inmediata proximidad al extenso llano de Bot, de notable potencial agrícola, a lo que debe añadirse la eventual explotación de los terrenos, más secos, sin embargo, de la propia collada.

El conjunto del Coll del Moro consta de tres sectores de necrópolis (Calars, Camp Teuler y Maries) y un hábitat (Fig. 1B), localizado entre Camp Teuler y Maries. El área excavada de este último, relativamente pequeña, se sitúa sobre un espolón triangular de unos $3.300 \mathrm{~m}^{2}$, que se proyecta, a una cota ligeramente inferior, hacia el sureste. Se halla actualmente separada del resto del yacimiento por la mencionada carretera (Figs. 2-4). El sondeo C.20 practicado en 1982 en el extremo meridional de este espolón permitió comprobar que el yacimiento lo ocupaba en su totalidad (Rafel y Blasco 1994: 32). En el extremo septentrional del área excavada se levanta una gran torre que constituye la construcción más célebre y divulgada del hábitat.

El yacimiento es conocido sobre todo por las intervenciones en las décadas de los ochenta y noventa, que mencionaremos más adelante. Entre 2014 y 2019 un equipo de investigación de la Universidad de Barcelona y el Instituto Catalán de Arqueología Clásica ha realizado trabajos de excavación y prospección geofísica en la zona de hábitat, así como una prospección pedestre en esta última y en las zonas bajas que se extienden al sur y al este. Estas intervenciones aportan nueva información sobre la entidad y características del hábitat, y sobre la ocupación del territorio, pero tan solo se ha publicado un pequeño avance sobre la excavación (Jornet et al. 2016). En el presente trabajo se presentan sus resultados, así como una revisión de los datos obtenidos por nuestros predecesores. Todo ello permite una nueva interpretación global, con importantes implicaciones en relación a la estructura del poblamiento de la zona y a la organización de la sociedad ibérica.

\section{INTERVENCIONES PREVIAS}

La primera mención al Coll del Moro se debe a Bosch Gimpera en 1914, en su diario de excavaciones inédito de San Antonio de Calaceite, desde donde se desplaza y describe restos de paredes cortadas por la carretera y cerámica ibérica ${ }^{1}$. Las intervenciones en la necrópolis comenzaron en 1953 (Vilaseca 1954) y se intensificaron entre 1971 y 1974 , pero los resultados apenas se divulgaron (Ferrer 1982, 1986) hasta la tesis doctoral de N. Rafel (1989, 1991). N. Rafel, F. Puig, D. Molas y G. Hernández (Molas et al. 1986, 1987a, 1987b; Rafel y Hernández 1992; Rafel 1993) las reanudaron en 1984 (sector Maries) hasta principios de los años 90. Fecharon el conjunto funerario desde finales del siglo IX a. C. a los siglos V-IV a. C. (Rafel 1989: 35-42, 1991: 135-142), pero la gran mayoría de tumbas corresponde al Bronce Final y Primera Edad del Hierro.

El hábitat fue excavado entre 1972 y 1976 (Berges y Ferrer 1976; Ferrer 1982). La Generalitat de Catalunya adquirió los terrenos en 1982 y se iniciaron intervenciones programadas hasta mediados de los años 90, a cargo de N. Rafel, F. Puig, M. Blasco y M. T. Miró (Rafel y Blasco 1991, 1994; Rafel et al. 1994; Blasco y Rafel 1995). En 2006 y 2007 se realizaron dos campañas de excavación y consolidación, dirigidas, respectivamente, por D. Garcia e I. Moreno, y por D. Garcia y N. Rafel (Rafel et al. 2015). Finalmente, se han realizado trabajos de consolidación, efectuados en 2012 y 2018 por las empresas Àtics y Món Iber Rocs respectivamente. Hubo también prospecciones superficiales en el hábitat sobre la cima de la collada, al norte de la carretera, que no implicaron una recolección, delimitación, ni documentación sistemática (Rafel et al. 2015: 11).

\footnotetext{
${ }^{1}$ P. Bosch Gimpera: Diaris d'excavació. Manuscrito conservado en el Museo de Arqueología de Cataluña-Barcelona, páginas 30-33 y 46-59.
} 

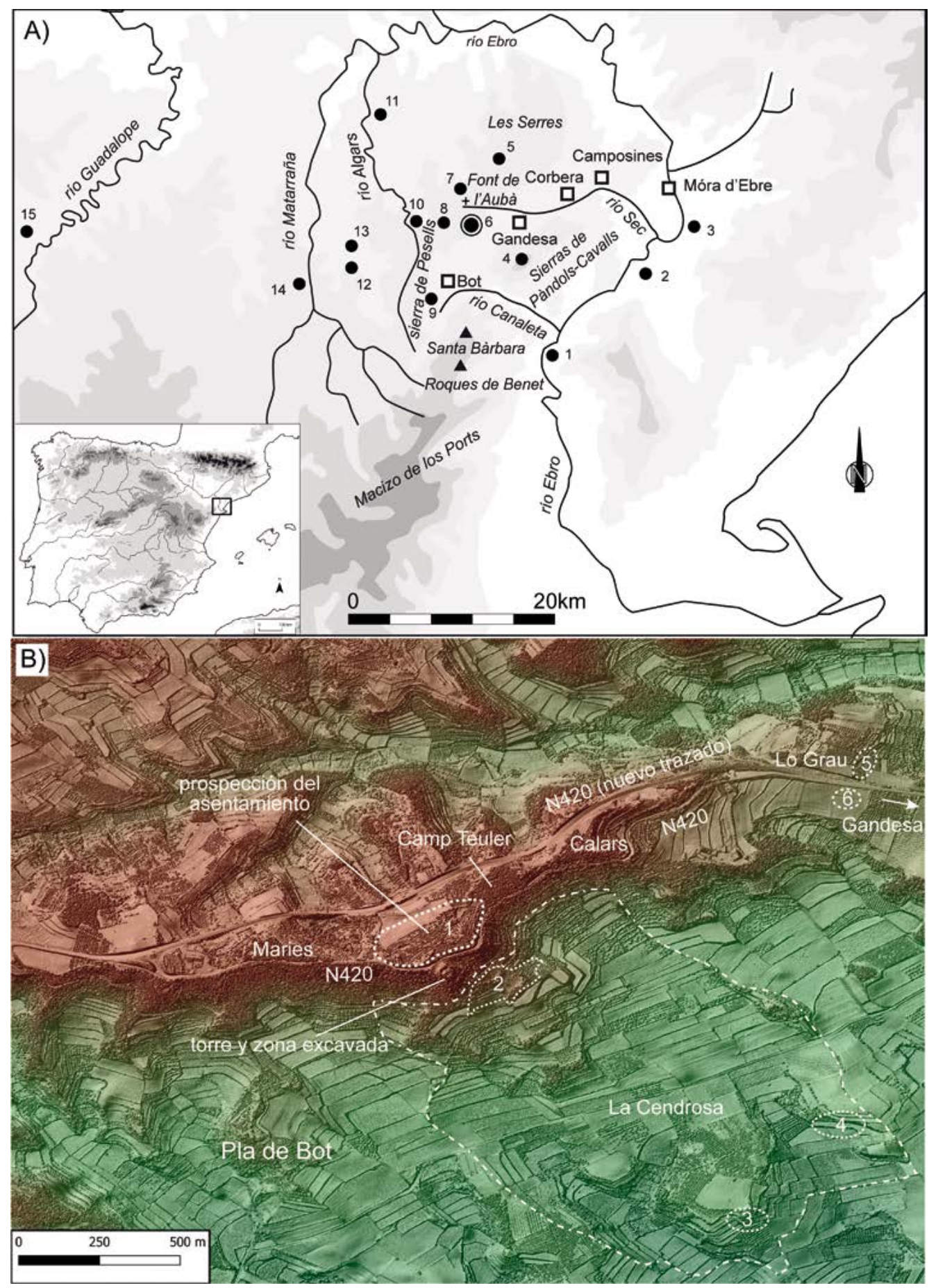

Fig. 1. Situación del área de estudio en la península ibérica, localizando los asentamientos citados en el texto: A. 1. Aldovesta; 2. Barranc de Gàfols; 3. Castellet de Banyoles; 4. Talaia de Puig Cavaller; 5. Coll del Moro del Xollat; 6. Coll del Moro de Gandesa; 7. Coll del Moro del Borrasquer; 8. Tossal de Sorio; 9. Tossal del Moro de Bot; 10. La Gessera; 11. Tossal del Moro de Pinyeres; 12. Els Castellets; 13. San Antonio de Calaceite; 14. Torre Cremada; 15. El Palao. B. Configuración general del conjunto arqueológico del Coll del Moro. 1. Zona prospectada en la cima de la collada; 2-4. Principales yacimientos localizados en la prospección de la zona de la Cendrosa; 5 . Asentamiento de Lo Grau del siglo I a.C.; 6. Asentamiento de Lo Grau de los siglos I-II d.C. (elaboración Pau Valdés sobre fondo LiDAR del Institut Cartogràfic i Geològic de Catalunya - ICGC) (en color en la versión electrónica). 


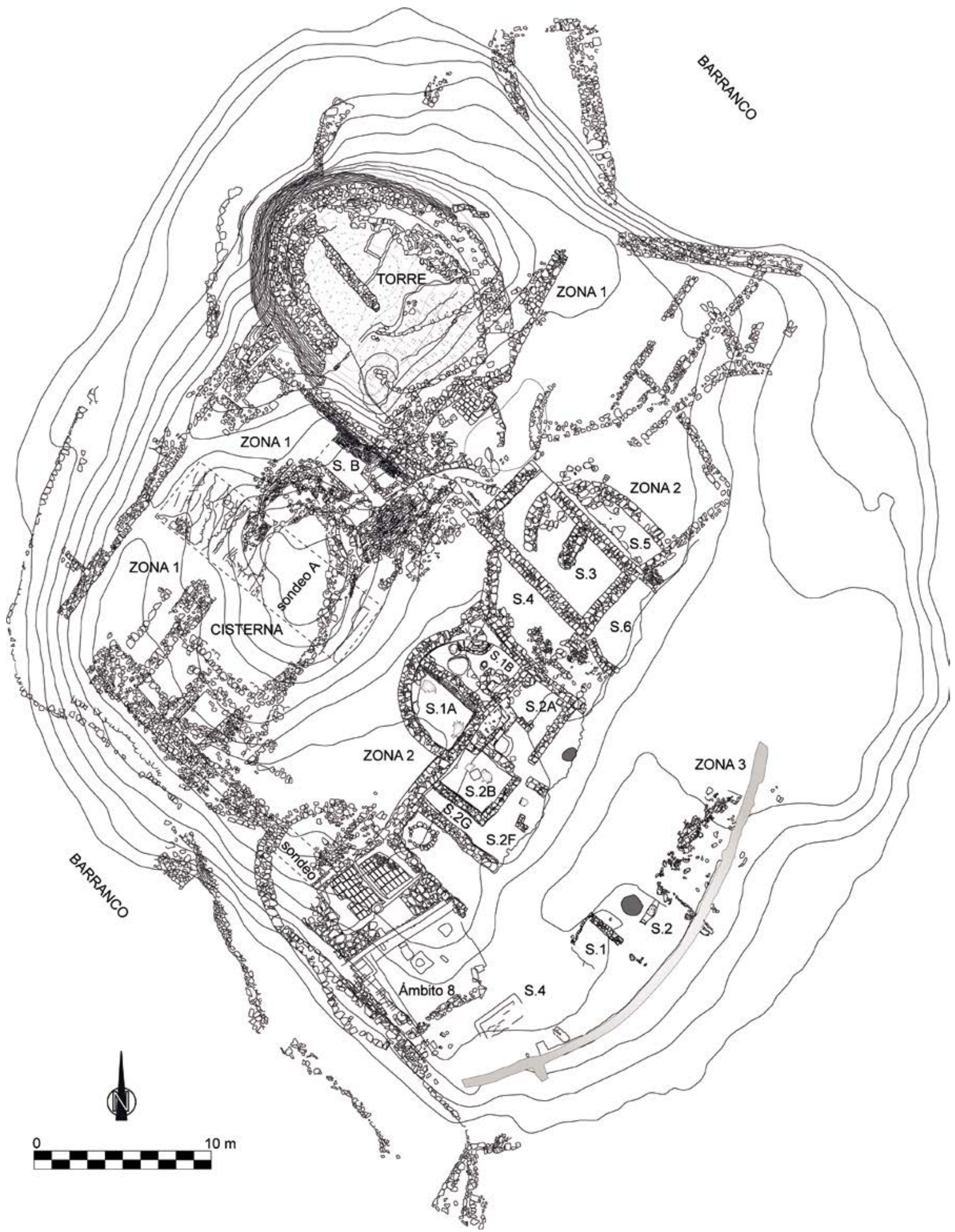

Fig. 2. Planta general del Coll del Moro de Gandesa (2019) (Instituto Catalán de Arqueología Clásica - ICAC).

Trab. Prehist., 77, N. ${ }^{\circ}$ 1, enero-junio 2020, pp. 113-129, ISSN: 0082-5638

https://doi.org/10.3989/tp.2020.12249 


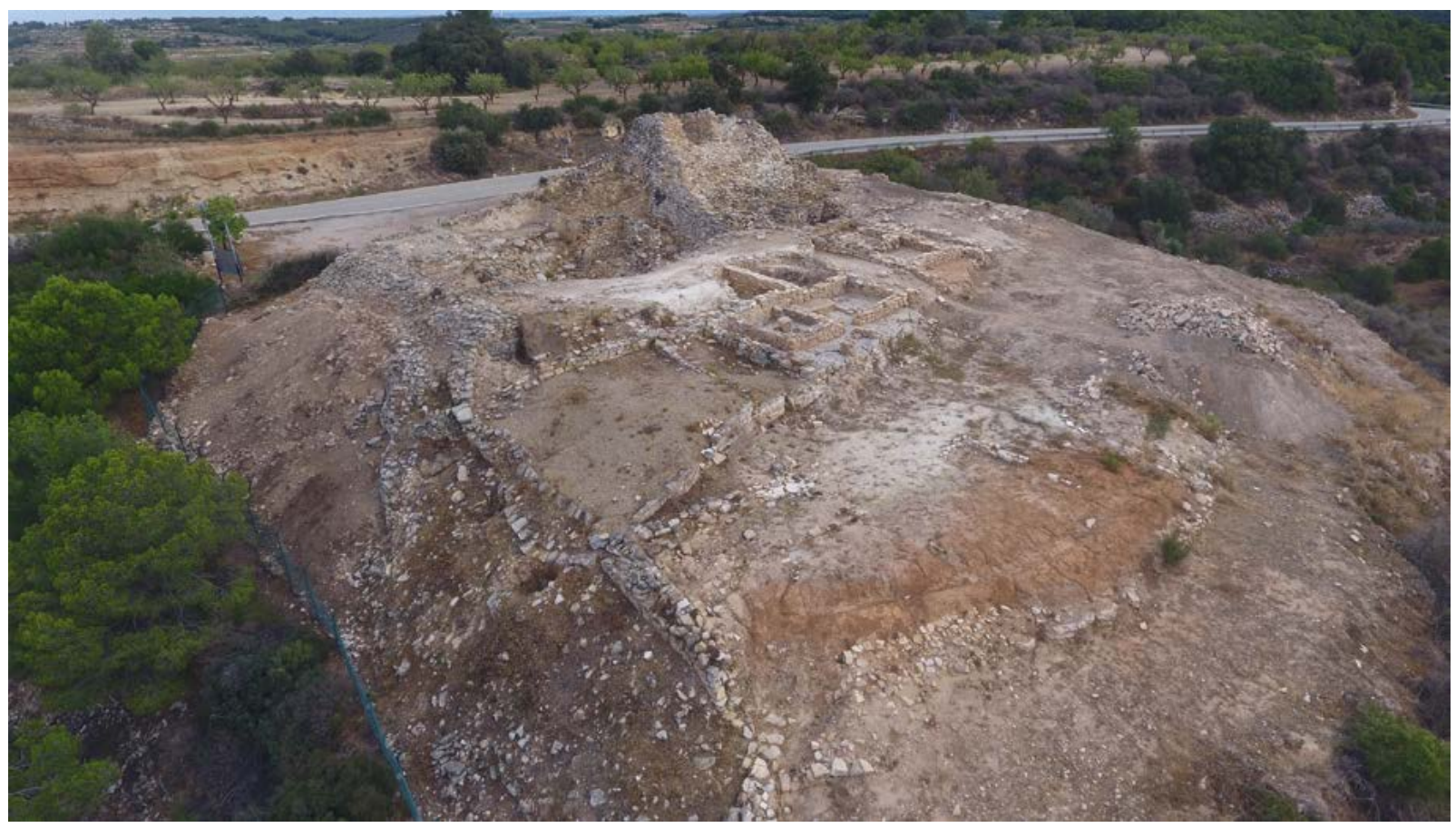

Fig. 3. Vista del Coll del Moro de Gandesa desde el sur (2019) con la carretera N-420 (foto X. Sicart, en color en la versión electrónica)
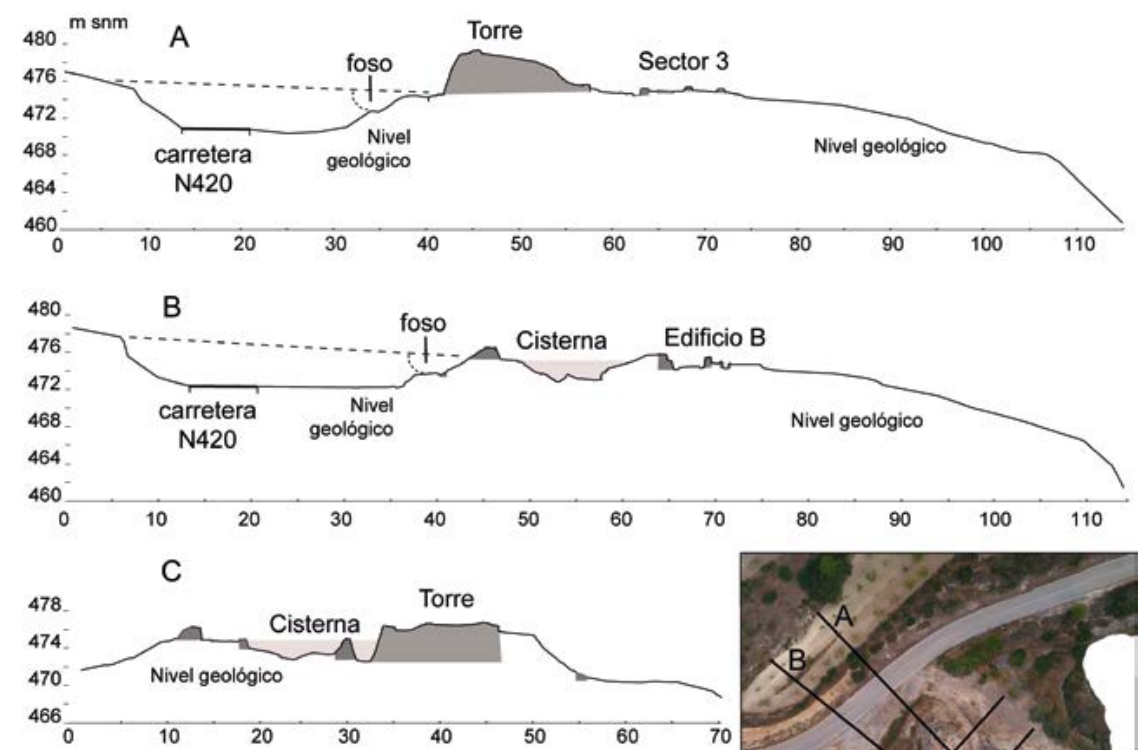

D
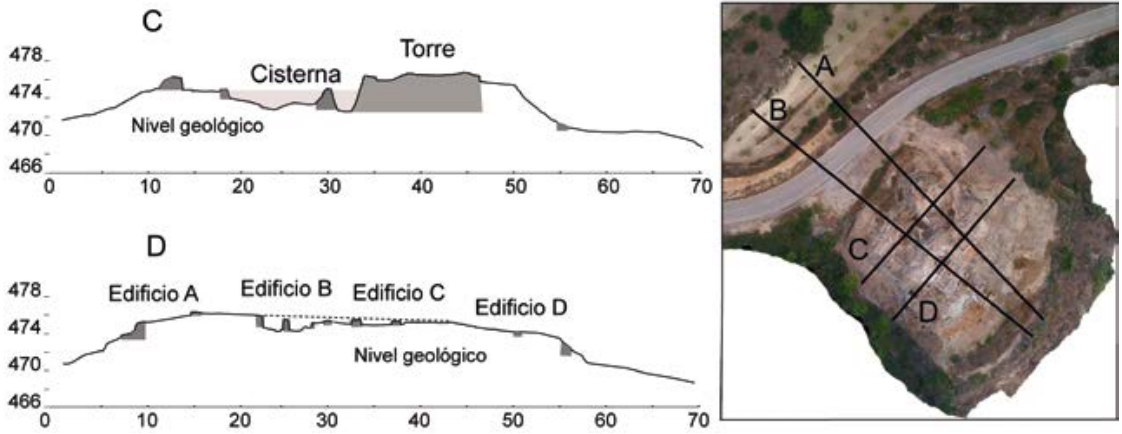

Fig. 4. Secciones generales de la zona excavada del Coll del Moro de Gandesa (Instituto Catalán de Arqueología Clásica - ICAC sobre foto X. Sicart, en color en la versión electrónica). 


\section{SECUENCIA OCUPACIONAL DEL HÁBITAT}

\author{
EI Primer Hierro y el período Ibérico Antiguo \\ (Fig. 5, 1)
}

Rafel y Blasco (1994: 33) hallaron en el sector de hábitat fragmentos descontextualizados de ánfora fenicia de aspecto arcaico y piezas de cerámica a mano atribuibles al Primer Hierro, lo que sugiere una ocupación durante el siglo VII a. C. y/o principios del VI. Nuestros trabajos han proporcionado restos similares, incluyendo un borde de ánfora tipo 10.1.2.1 (Fig. 6: 1).

La más antigua acción humana documentada estratigráficamente en ese sector es un gran recorte practicado en el nivel geológico, de forma aproximadamente rectangular. Mide unos 19 por $9 \mathrm{~m}$ en su parte superior. Su profundidad media es de unos 3,5 m, pero en algún punto alcanza los 4,5 m (Rafel et al. 2015: 8). Está revestido por paredes ataludadas de piedra, reconocidas por nuestros predecesores en los lados meridional, septentrional y oriental, y por nosotros en el occidental. La oriental es, a su vez, la parte inferior de la pared oeste de la gran torre exenta que preside el asentamiento, lo que permite afirmar su unidad estructural. La propuesta inicial lo interpretaba como un foso (Rafel y Blasco 1994: 33-34), pero otra posterior, más razonable, como una cisterna o balsa, que habría podido contener unos $300 \mathrm{~m}^{3}$ de agua (Rafel et al. 2015: 8). Según Rafel y Blasco (1994: 34), este recorte se colmató entre finales del siglo $\mathrm{V}$ y el siglo III a. C. En los niveles más profundos el único material de importación era un fragmento informe de ánfora fenicia. Los cubría un estrato de derrumbe que contenía diversos fragmentos de copa Cástulo -inéditos-, lo que llevó a fecharlo en el último cuarto del siglo $\mathrm{V}$ a. C. La colmatación prosiguió durante los siglos IV y III a. C. (Rafel y Blasco 1994: 19 y 34).

La torre es de planta elipsoidal, de base maciza (Rafel et. al. 2015: 17), y con el lado corto sudoriental de trazado rectilíneo, tal vez por una refacción. Se asienta sobre la roca y mide 14 x $18 \mathrm{~m}$, con una altura conservada de $8,65 \mathrm{~m}$. Está constituida por dos muros concéntricos adosados, quizá construidos de una sola vez. La cerámica ática de mediados o segunda mitad del siglo $\mathrm{V}$ a. C. hallada en los niveles inferiores de la cisterna sugiere su construcción antes del siglo IV a. C., pero podría remontar al siglo VI a. C., o incluso antes. El indicio más sólido en este sentido procede del primer pavimento interior: entre este y el macizado de base de la torre se halló un enterramiento de individuo perinatal con un colgante esferoidal de bronce, de un tipo fechable entre finales del siglo VII y la primera mitad del siglo $\mathrm{V}$ a. C., pero particularmente frecuente en el siglo VI a. C. (Rafel et. al. 2015:
14 y 15, fig. 9, 1). La presencia de un gran recipiente a torno permite acotar esta datación entre la segunda mitad del siglo VI y mediados del V a. C.

\section{Siglo III a. C. (Fig. 5, 2)}

Se ha documentado otro momento de ocupación por encima del suelo de la torre recién descrita, cuando un muro de piedra divide longitudinalmente en dos su espacio interior. En la parte oriental había varias estructuras de adobe: una, cuadrada $(1,20 \mathrm{~m})$, posiblemente era "una artesa o bien ... un compartimento destinado al almacenaje de alimentos u objetos" (Rafel et al. 2015: 12); entre las restantes, muy deterioradas, había un posible horno. La datación puede situarse en el siglo IV a. C., ya que en el derrumbe había un borde de cuenco forma Lamb. 22 (Fig. 6: 2), coherente con otros hallazgos, descontextualizados, de cerámica ática (Fig. 6: 3-7).

La presencia en la torre de un cuenco del Taller de Rhode forma Lamb. 27 (Fig. 6: 8) y de una dracma de imitación emporitana (inédita) certifica la continuidad de su ocupación durante el siglo III a. C. Según nuestros trabajos de excavación, también en esta centuria, tal vez en un momento ya muy avanzado de la misma, se erigió un gran edificio fortificado, probablemente una residencia aristocrática, al sur y sureste de la torre. Además, todo el espolón donde se encuentran la torre, el edificio y la cisterna, ya colmatada, se aisló del resto del hábitat mediante una excavación (seguramente un foso) que discurre en paralelo a la cara occidental de la cisterna y de la torre, hasta alcanzar los cursos de los torrentes que delimitan el espolón por el noreste y el suroeste. La anchura de este posible foso es desconocida, ya que la carretera destruyó su límite noroccidental. Un grueso muro de contención de trazado paralelo al del gran edificio fortificado delimitó este nuevo espacio al noroeste y suroeste. Por el noreste los límites aún no están bien definidos, pero las potentes estructuras identificadas por los trabajos de 2019 podrían tener las mismas funciones. Esta profunda remodelación probablemente se vincula a cambios importantes en la función y simbolismo de esta parte del yacimiento. Tal vez refleje una profundización de las diferencias sociales y la separación no solo simbólica, sino también física, de la elite que controlaba el asentamiento. Además, las preocupaciones defensivas -sin duda acuciantes en el último tercio del siglo III a. C.- pudieron jugar un papel importante en esta remodelación. Ambas explicaciones no son recíprocamente excluyentes. Al contrario, el clima creado por la intervención bárquida en la península ibérica -cuyo reflejo creemos advertir, no lejos del Coll del Moro, en la fundación de la ciudad del Castellet de

Trab. Prehist., 77, N. ${ }^{\circ}$ 1, enero-junio 2020, pp. 113-129, ISSN: 0082-5638

https://doi.org/10.3989/tp.2020.12249 


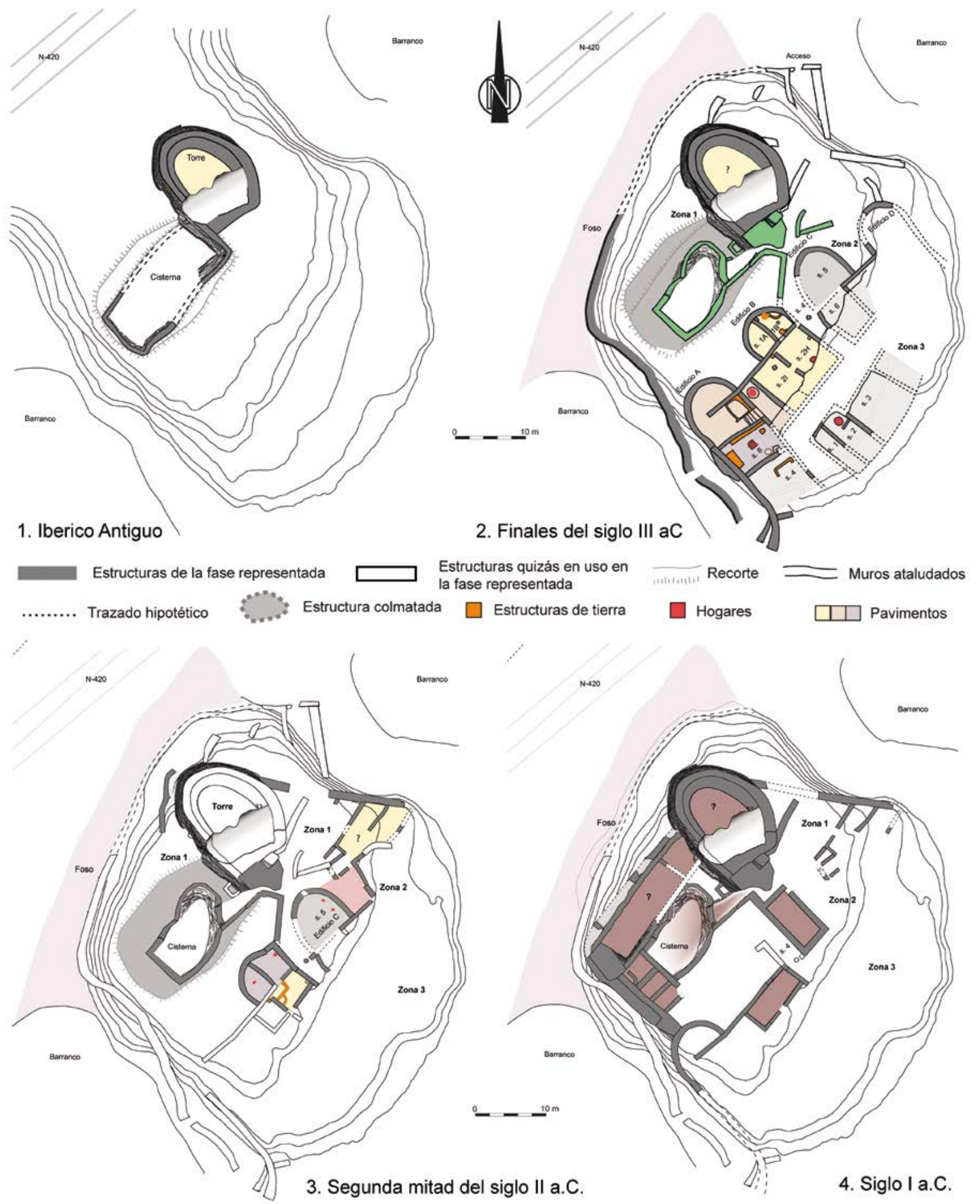

Fig. 5. Plantas esquemáticas que indican la evolución estructural de la zona excavada del Coll del Moro de Gandesa: 1. Período ibérico antiguo; 2. Finales del siglo III a.C.; 3. Segunda mitad del siglo II a.C.; 4. Siglo I a.C. (en color en la versión electrónica). 


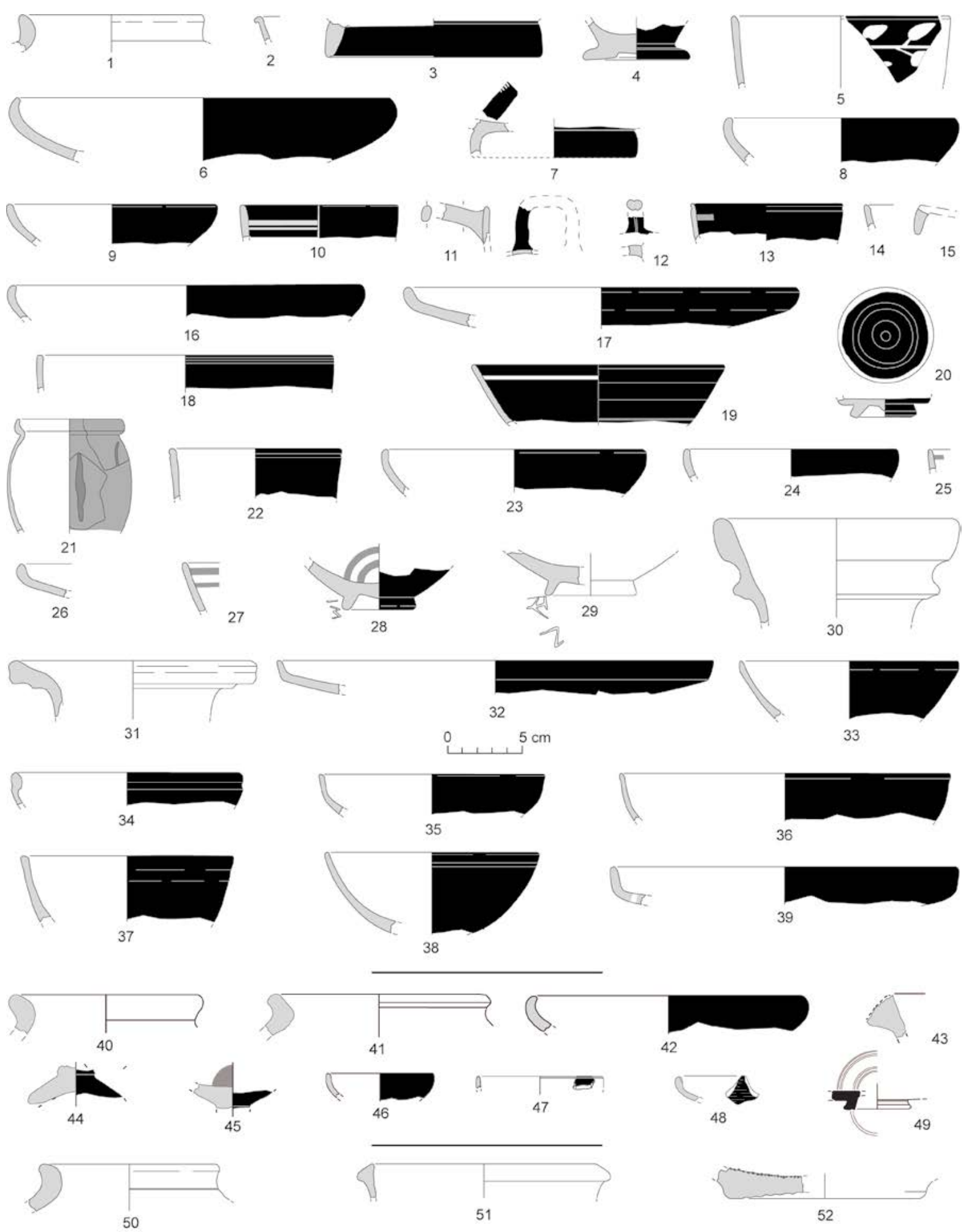

Fig. 6. Coll del Moro de Gandesa. Materiales cerámicos de importación procedentes de la zona excavada del asentamiento (1-39), de la prospección de la zona al norte de la carretera (40-49) y de la prospección del Pla de Bot (50-52).

Trab. Prehist., 77, N. ${ }^{\circ}$ 1, enero-junio 2020, pp. 113-129, ISSN: 0082-5638

https://doi.org/10.3989/tp.2020.12249 
Banyoles (Sanmartí et al. 2012: 59-60)-, pudo provocar el reforzamiento de las elites ante una situación de inseguridad. También podría interpretarse así la reocupación a finales del siglo III a. C. de la necrópolis de Santa Madrona, cuyo uso anterior remonta a la Primera Edad del Hierro (Belarte y Noguera 2007: 65).

El edificio fortificado ocupó probablemente, de suroeste a noreste, toda la zona 2 del espolón, ahora aislada por completo. Su construcción recortó los mismos estratos de margas en que se había excavado la cisterna. Los muros externos conservados del nuevo complejo se adosan a este recorte y delimitan unos recintos de carácter semisubterráneo. Ello ha facilitado la conservación de su área septentrional, pero poco subsiste de la parte superior, sobre el nivel externo de circulación. Las estructuras situadas inmediatamente al sur han desaparecido a causa de trabajos modernos de aterrazamiento. Ello dificulta la delimitación e interpretación del conjunto, conformado, al menos, por cuatro edificios (A, B, C y D de suroeste a noreste). Cada uno tiene una cabecera semicircular de 6-7 $\mathrm{m}$ de diámetro $\mathrm{y}$, al menos los tres primeros, están unidos por muros que prolongan sus bases. La diferente separación entre las cabeceras de los edificios A, B (5 m) y B, C (solo $3,2 \mathrm{~m}$ ) sugiere que existió una puerta entre B y C, situada a la altura de los muros diametrales de los cuerpos semicirculares.

El límite suroccidental de este conjunto es la continuación hacia el sur del muro exterior del cuerpo absidal del edificio A. Dicho muro sigue el borde del espolón en una longitud actualmente indeterminada. Los otros límites son desconocidos. El grosor de los muros exteriores $(0,60$ a $0,70 \mathrm{~m})$ les confiere un cierto valor defensivo, coherente con esos cuerpos semicirculares avanzados, que permitirían el flanqueo de eventuales asaltantes. También permite suponer la existencia original de uno o incluso dos pisos, que se elevarían por encima del nivel de margas recortadas para encajar los edificios. La superficie de las margas era, pues, el nivel de circulación exterior entre el conjunto que describimos y la base de la torre del Ibérico Antiguo. Ello, unido a las dimensiones y aspecto externo del complejo, sugiere un carácter monumental.

Las funciones de las partes conocidas de estos edificios parecen relacionadas con la transformación de materias primas -producción textil (edificio A) y de vino (edificio B)-, pero las actividades rituales también están documentadas. N. Rafel, M. Blasco y J. Sales (1994) descubrieron dos depósitos impermeabilizados destinados al enriado de lino (Alonso y Juan 1994), situados en el ámbito 7, que antecede el cuerpo semicircular. Además, aparecieron 107 pesas de telar en el estrato de derrumbe que cubría la mencionada instalación, procedentes probablemente de un piso superior. Un sondeo practicado en el cuerpo semicircular "pro- porcionó una gran cantidad de tinajas y grandes recipientes... que permiten suponer la existencia de un almacén" (Rafel et al. 1994: 123), tal vez sin relación con el taller textil. La presencia en el derrumbe de un cuenco del Taller de las Pequeñas Estampillas, un fragmento de una copa o de un guttus de campaniense A y otros indicios de menor entidad fijaron la cronología final en las postrimerías del siglo III a. C. (Rafel et al. 1994: 131, fig. 8, y 132-133).

Inmediatamente al sureste del taller textil, a un nivel inferior y adosado al límite occidental, existe una estancia rectangular (ámbito 8) con bancos corridos de adobes en los costados noroeste y suroeste, un depósito cuadrangular de adobes en el ángulo occidental y esquineras de piedra o de arcilla en los otros, además de un hogar central. Se ha interpretado como un espacio con funciones rituales por el hallazgo in situ de una marmita y su tapadera de cerámica a mano con decoración geométrica y zoomorfa. En ella destacan el carnero y la cruz esvástica, cuyo simbolismo está arraigado en el culto al hogar y a los antepasados (Rafel et al. 2018). Los bancos corridos de adobe permiten relacionarlo con el edificio 10 del Castellet de Banyoles, al que también se atribuye una función ritual (Sanmartí et al. 2012: 56-59).

El edificio B está compuesto por un recinto absidal (sector 1), de $8 \times 5,5 \mathrm{~m}$, dividido en dos espacios (1 $\mathrm{A}$ y 1B) por una pared sin aberturas. Los muros conservan hasta $1,60 \mathrm{~m}$ de altura. Como los del edificio $\mathrm{A}$, revisten el recorte practicado en las margas, de modo que estos recintos eran prácticamente subterráneos. Inmediatamente al sur (sector 2) unos muros rectilíneos delimitan cuatro espacios: 2A, 2B, 2C-D, 2F-G. Su probable acceso desde el sur no puede confirmarse porque los muros de C-D y F-G están en gran parte destruidos por el bancal antes mencionado. La puerta PR2029 comunicaba en un principio los sectores 1 y 2. Se ha observado que el espacio cuadrangular al sureste del cuerpo absidal fue remodelado durante el período ibérico, subdividiendo los dos recintos rectangulares iniciales $(2 \mathrm{H}$ y $2 \mathrm{I})$ en otros menores $(2 \mathrm{~A}, 2 \mathrm{~B}$, $2 \mathrm{C}-\mathrm{D}$ y $2 \mathrm{~F}-\mathrm{G})$, y tapiando aparentemente las puertas para aislarlos del cuerpo semicircular.

El edificio fue destruido muy probablemente en torno a 200 a. C., según muestra la presencia de cerámica campaniense $\mathrm{A}$ en los niveles de derrumbe: un borde de copa forma Lamb. 42bc, un borde y un asa de copa Morel 68 y un borde de cuenco Lamb. 27, (Fig. 6: 9-12). Los abundantes restos de tinajas y de pondera indican la existencia de un piso superior, tal vez accesible por el norte desde el nivel de circulación exterior de margas. Como en el edificio A, los espacios superiores parecen tener la función de almacén, utilizando tanto grandes recipientes cerámicos (un $40 \%$ de los vasos hallados) como de tierra cruda. Los restos 
carpológicos de Vitis vinifera muestran que alguno por lo menos debió de contener uva o vino.

En el sector 1A se hallaron dos pequeñas fosas excavadas en el nivel geológico (regularizado como suelo). Una contenía una mandíbula infantil, lo que sugiere una función ritual. Sobre el pavimento del sector $1 \mathrm{~B}$ se documentaron tres piedras superpuestas intencionalmente, soportes y depósitos elaborados en tierra. Bajo uno de ellos aparecieron sendas inhumaciones de un perinatal y de un ovicaprino. Existen también indicios de actividad ritual en los recintos $2 \mathrm{~A}$ y $2 \mathrm{~F}$ (ofrendas en fosas bajo los niveles de uso). En el 2A, que tiene función productiva, hay dos inhumaciones de perinatales. La asociación de prácticas rituales y actividades económicas está documentada en otros yacimientos ibéricos, como Olèrdola, con varias inhumaciones de perinatales en un taller metalúrgico y en una tintorería/tenería, datados entre mediados del siglo IV y el siglo III a. C. (Crespo et al. 2011).

El sector $2 \mathrm{~A}$ (unos $5 \times 3 \mathrm{~m}$ ) es de planta rectangular. Es probable que, ya en el siglo III a. C., albergase un lagar o almazara semejante al que se documentará allí en el siglo II a. C. (véase más adelante). El sector 2B (4 x $4 \mathrm{~m})$ tenía una estructura central de tierra en forma de prisma cuadrangular. Dos pequeñas fosas adyacentes contenían sendos ganchos de hierro, tal vez destinados a fijar en ella algún elemento de material perecedero. La función del recinto es desconocida, pero los estudios carpológicos de D. López Reyes han descubierto numerosas semillas de Vitis vinifera en el nivel de destrucción, lo que sugiere una relación con la posible almazara de la vecina estancia $2 \mathrm{~A}$. El sector 2C-D, conservado parcialmente, era el único con probable función doméstica, ya que poseía un hogar. En el sector $2 \mathrm{~F}$ no se han documentado estructuras, pero sí una fosa con restos de un ritual de fundación: cuenta de collar, vaso a mano en miniatura, falanges de suido.

Como ya se ha dicho, las labores agrícolas han destruido casi toda la parte suroriental del conjunto formado por los edificios A-B-C: un espacio de unos $6 \mathrm{~m}$ de anchura por unos $20 \mathrm{~m}$ de longitud. En la zona 3 , al sureste de esta zona arrasada hay dos o tres recintos yuxtapuestos de los que solo se conserva parte de tres muros, pero que permiten reconocer las dimensiones aproximadas de uno de ellos $(5 \times 3,3 \mathrm{~m})$, con un hogar en el centro.

Parte del área arrasada debió de estar ocupada por un espacio de circulación, según indica la ausencia de estructuras excavadas como las del edificio B. Sin embargo, los edificios A-B-C de la zona 2 podrían haber ocupado parte de la zona 3, en particular en el extremo occidental. Allí, inmediatamente al sur del edificio A, hay una plataforma rectangular con pavimento de adobes, delimitada por un murete de tierra (UE 3013), interpretable como una estructura artesanal relacionada con este edificio.

Creemos probable que los edificios con cabecera absidal y las construcciones inmediatamente al sur constituyeran una gran mansión fortificada, tal vez con patio central, que incluiría áreas destinadas a producciones especializadas (tejido y vino), a funciones cultuales y residenciales. Este complejo perduró hasta una fecha en torno a 200 a. C., cuando se produjo un incendio generalizado.

Conocemos casos similares en el vecino territorio del Matarraña. El más evidente es el de los Castellets (Cretas), un pequeño complejo residencial $\left(500 \mathrm{~m}^{2}\right)$, dotado de dos bastiones absidales, separado, como en Coll del Moro, de un posible hábitat más extenso (Burillo 1991: 49). En San Antonio de Calaceite, según Bosch $^{2}$, hubo dos estructuras absidales en el interior del asentamiento, flanqueando la entrada al complejo edilicio de mayor entidad. Este, como el de Coll del Moro, combinaba la función residencial con las actividades rituales, productivas y de almacenaje (Jornet 2017: 85 y 273).

La cisterna estaba ya colmatada en el siglo III a. C., según se deduce de la excavación del foso tan solo unos $6 \mathrm{~m}$ más al norte, así como de los hallazgos en los niveles superiores del llamado "corte B". Estos incluyen esencialmente vasos de campaniense A de las formas Morel 68, Lamb. 27 (sobre todo), 26 y 28, así como fondos estampillados, además de "diversos fragmentos sin forma de producciones precampanienses (sic) del taller de las pequeñas estampillas" (Rafel y Blasco 1994: 19)3. Todo ello indica una datación en torno a 200 a. C. Las pocas piezas de importación del "corte B" localizadas por nosotros (limpieza de perfiles) confirman esta cronología, ya que se trata de campaniense A antigua (Fig. 6: 13-16). Es posible, pero no seguro, que este espacio estuviera ocupado por algunas construcciones, pero quedó muy alterado a finales del siglo III a. C. por la excavación de una nueva cisterna, que habría destruido las que hubiera.

Este segundo depósito, menor $(15 \mathrm{~m} \mathrm{x} 8 \mathrm{~m})$, recortó la sedimentación formada dentro de la primera cisterna. Sus paredes fueron forradas con muros de piedra, aprovechando parcialmente los de esta. Los materiales de sus niveles inferiores -campaniense A antigua (Fig. 6: 22-25)- confirman una cronología en

\footnotetext{
2 Bosch Gimpera, P. Inédito. Planta de Sant Antoni. Fons de l'Arxiu del Museu d'Arqueologia de Catalunya-Barcelona. Publicada en Jornet 2017 (fig. 9.13 , p. 85 y fig. 9.18, p. 90)

3 También se menciona una pieza de forma Lamb. 5, evidentemente más tardía, y un fragmento de pie atribuido a la forma Morel 2283 d1. Albergamos algunas dudas sobre su correcta clasificación (o la pertenencia al mismo nivel estratigráfico). No se han publicado dibujos de estas piezas, que tampoco se han localizado en los almacenes de las instituciones que tienen encomendada su custodia.
} 
torno a 200 a. C. Con esta estructura se relaciona una canalización habilitada contemporáneamente cerca del ángulo meridional de la torre. Está delimitada al norte por una plataforma adosada a la torre y por un muro que se prolonga hacia el oeste hasta la nueva cisterna. Al sur, la definen una refacción del forro ataludado de la cisterna antigua y un muro que se prolonga en dirección sureste para girar bruscamente hacia el sur en dirección al cuerpo absidal del edificio B. Parece adosarse al mismo, lo que reduce de modo considerable la anchura de esta vía de paso al interior de la gran mansión fortificada. Ello implicaría que la conducción $\mathrm{y}$, con alguna duda, la propia cisterna, fueron habilitadas en un momento posterior -aunque no mucho- a la erección del gran edificio fortificado. Lo mismo cabría decir de la escalera construida sobre la plataforma que delimita por el norte la conducción, tal vez relacionable con una rehabilitación de la torre.

\section{El período Ibérico Tardío (Fig. 5, 3)}

Es posible que durante varios decenios después del incendio el lugar quedara abandonado, pero en la segunda mitad del siglo II a. C. se reocuparon, como mínimo, los edificios B y C. Por una parte, se rebajaron los niveles de uso y de derrumbe formados durante el siglo III a. C. para reinstalar el lagar del sector 2, intervención fechada a partir de un borde de pátera Lamb. 5 de campaniense A, hallado en el nuevo pavimento (Fig. 6, 17). El lagar consiste en una plataforma elevada de adobes, que comunica mediante un orificio con una fosa excavada en la roca. Su función ha sido confirmada por análisis de química orgánica, realizados por A. Pecci, que han documentado la presencia de ácido tartárico y siríngico. Estructuras semejantes asociadas a la vinificación abundan en el área valenciana (Pérez Jordà 2000; Mata et al. 2009). Los cuerpos absidales de los edificios $\mathrm{B}$ y $\mathrm{C}$ fueron también reutilizados y parcialmente remodelados, en este caso sobre los estratos de derrumbe que colmatan las partes subterráneas de las construcciones. En los nuevos niveles de uso se documentan hogares lenticulares. Es de suponer que la segunda cisterna siguiera en uso en este momento.

\section{La ocupación de época romana (Fig. 5, 4)}

A finales del siglo II a. C., o quizá ya en la centuria siguiente, se produjo una importante remodelación: se erigió un gran edificio en torno a un espacio central abierto donde se hallaba, quizá todavía en uso, la segunda cisterna. Los restos conservados se distribuyen en cuatro alas en torno al espacio central. La noroeste y suroeste están construidas ex novo -aunque la segunda en parte sobre el muro de forro de la segunda cisterna- y las otras dos reaprovechan parcialmente edificios anteriores. Las dimensiones actualmente conocidas del conjunto son de $26 \mathrm{~m}$ en dirección noreste-suroeste, por un mínimo de 30 en dirección noroeste-sureste. No puede excluirse que se extendiera también al este de la torre, donde se han descubierto, en 2019, algunas estructuras todavía sin datación precisa.

Por el lado suroeste el edificio está delimitado por un grueso muro $(1,6 \mathrm{~m})$ con un mínimo de cuatro recintos adosados (S1-S4). Se excavaron a principios de los 1990, pero carecen de una publicación mínimamente detallada y de datación precisa a partir de las importaciones, que siguen inéditas e ilocalizables. En el lado sureste, y superpuesto en parte al edificio absidal C, se construyó un recinto rectangular (sector 3 de la zona 2) de 7,5 por 3,5 m, dotado de una pequeña puerta cerca del ángulo septentrional. El hallazgo de cerámica del círculo de la campaniense B (forma Lamb. 5) en el nivel de uso ha permitido fecharlo a partir de finales del siglo II a. C. Inmediatamente al oeste se construyó un muro paralelo a esta estructura, que tal vez perpetúa el corredor de acceso, aunque invirtiendo el sentido de circulación. Además, sobre el nivel de derrumbe del lagar del siglo II a. C., entre las paredes que conforman los recintos $2 \mathrm{~A}$ y $2 \mathrm{~B}$, se formó un estrato (UE 2008) que contiene campaniense A tardía (Fig. 6: 19), cerámica del círculo de la campaniense B (formas Lamb. 1 y 2) (Fig. 6: 18 y 20) y un cubilete de paredes finas de la forma Mayet II (Fig. 6: 21). Ello viene a coincidir con la cronología propuesta para el sector 3 y demuestra la continuidad de uso del edificio B. Esta datación es coherente con el hallazgo en niveles superficiales de siete monedas ibéricas de bronce (cecas de Kese, Kelsa, Salduie, Tamaniu y Belikion) fechables entre 125 y 75 a. C. No es seguro que estas construcciones constituyeran el límite sureste del conjunto tardo-republicano, pero el arrasamiento del sector situado más allá de las mismas impide mayores precisiones. Finalmente, el espacio central abierto quedaba delimitado por la antigua torre $\mathrm{y}$ el recinto rectangular superpuesto al edificio $\mathrm{C}$.

Persisten incógnitas sobre la estructura y la cronología de detalle de este edificio, pero está claro que su planta general recuerda -sin coincidir plenamente con ella- la de distintos edificios romano-republicanos erigidos en el noreste de la península ibérica. Cuentan invariablemente con espacios abiertos cuadrangulares de dimensiones variables, delimitados por construcciones más o menos complejas en los cuatro costados, y a menudo con cisterna central. Es el caso de Can Tacó, de Puig Castellar de Biosca (Pera et al. 2016) y, tal vez también, de Mas Gusó (Casas et al. 2016), el Castellvell de Olius (Asensio et al. 2012) y Torre Crema- 
da II (Moret et al. 2006: 106-131). La estructura de los ejemplos mencionados es más regular, debido probablemente, en el caso de los dos primeros, a su erección ex novo, en lugares sin ocupación previa. Pero el conjunto del Coll del Moro comparte con ellos la forma general y, sobre todo, la ubicación junto a vías de comunicación, la amplia visibilidad sobre el territorio $y$, por supuesto, la datación en un momento ya bastante avanzado del período tardo-republicano.

La ocupación romano-republicana del Coll del Moro perduró hasta la segunda mitad del siglo I a. C., según muestran, p. ej. las cerámicas halladas en la cisterna fechables en el siglo I a. C.: ánforas púnicas tipo 7.5.2.3 (Fig. 6: 31), campaniense A tardía (Fig. 6: 26-29), vasos del círculo de la campaniense B como las páteras forma 5-7 y los cuencos forma Pasquinucci 127 (Fig. 6: 32-33), y, en particular, un ánfora bética del tipo Lomba do Canho 67 (Fig. 6: 30). Existen también niveles relacionados por el exterior con la torre que contienen sobre todo cerámicas tardías del círculo de la B (Fig. 6: 34-39), con formas como la Morel 2841 y Pasquinucci 127 que sugieren una cronología de mediados del siglo I a. C.

Berges y Ferrer (1976: 398) documentaron una ocupación en época imperial en el interior de la torre (una lucerna Loeschke VIII de finales del siglo II) y en una pequeña habitación, adosada a la propia torre y superpuesta al muro noroeste del recinto tardo-republicano. Se trata de una presencia muy limitada, tal vez un simple punto de observación. El práctico abandono del lugar precisamente a principios de época imperial confirma el carácter de punto de control estratégico que tuvo la última ocupación de época tardorepublicana.

\section{LA PROSPECCIÓN DE LA CIMA DE LA COLLADA (FIG. 1B, $\mathbf{N}^{\circ}$ 1)}

Los trabajos previos de prospección, no sistemáticos, habían documentado la presencia de materiales en la parte más elevada de la collada (Rafel et al. 2015: $37,44)$, sin definir con detalle su área de dispersión, su cronología o las características de la ocupación. Nuestro proyecto ha llevado a cabo campañas de prospección pedestre y geofísica mediante georradar y tomografía eléctrica. Las 3 ha de superficie prospectadas se sitúan al norte de la antigua carretera N-420, entre la necrópolis Teuler, al oeste, y la necrópolis Maries, al este. Las parcelas prospectadas, ocupadas por plantaciones de almendros (Fig. 7: 1), han sido identificadas mediante su referencia catastral $(14,34$, 35 y 37). No se obtuvo el permiso para la parcela 33 . Para mejorar la visibilidad del material y obtener resultados homogéneos, se solicitó a los propietarios que labraran previamente el terreno. Los equipos eran de siete personas, con apenas un metro de separación entre sí. Se recolectaron todos los materiales, recogidos por cuadros de unos $50 \mathrm{~m}^{2}$ determinados por la separación entre los almendros. La prospección se completó con la recuperación de metales mediante el uso de detectores, con fotografía aérea por medio de un dron y con prospección geofísica a cargo de la empresa SOT Archaeological Prospection.

Los resultados de la prospección con detectores de metales fueron relativamente pobres, debido al expolio sistemático por furtivos, pero en un sector de unos 300 $\mathrm{m}^{2}$, a $60 \mathrm{~m}$ al norte de la torre, se localizaron 26 fragmentos de escoria de hierro, indicio cierto de actividad metalúrgica (Fig. 7: 1).

La prospección pedestre proporcionó 9.234 fragmentos cerámicos de época protohistórica, con una densidad creciente de norte a sur, en dirección a la torre. Su dispersión permite sugerir los límites del asentamiento. Existe una gran densidad sobre una superficie de unas 2 ha, y hay que añadir 0,5 ha no prospectadas (parcela 33) o muy erosionadas por los trabajos agrícolas (sur de la parcela 35), otras 0,3 ha de la zona en curso de excavación, así como la superficie ocupada por el aparcamiento habilitado junto a la torre y el tramo adyacente de la carretera N-420. La superficie total del asentamiento sería, pues, de unas 3 ha.

La cronología de los 74 fragmentos de importación $(0,8 \%)$ coincide con la de los periodos de ocupación de la zona excavada, con predominio de la fase de finales del siglo III a. C. y principios del II a. C. Destacan 9 fragmentos de ánfora fenicia occidental del siglo VII o principios del VI a. C. y 7 de imitaciones de la misma (Figs. 6: 40-41 y 7: 2).

Del período ibérico hay dos fragmentos de cerámica ática de barniz negro (la pared de una copa y el borde de un cuenco forma Lamb. 21) (Fig. 6: 42). Las producciones del siglo III a. C. son un cuenco del Taller de las Pequeñas Estampillas y tres fragmentos del Taller de Rhode, entre ellos un borde de plato de pescado. La campaniense A es relativamente abundante, pero reducida a las formas 27, Morel 68, algún cuenco pequeño y un borde de pátera forma Lamb. 5 (Fig. 6: 44-48). También hay una base de pátera campaniense del círculo de la B (Fig. 6: 49). Las ánforas de importación son siempre itálicas o greco-itálicas (Figs. 6: 43 y 7: 6). Todo ello sugiere una ocupación más o menos continuada por lo menos desde el principio del siglo VI a. C., tal vez más intensa en los últimos decenios del siglo III a. C. Las formas de cerámica ibérica son muy diversas, aunque predominan las piezas de transporte y almacenaje (Fig. 7: 4). La cerámica a mano solo representa un 2,5\% del total (Fig. 7: 3). 

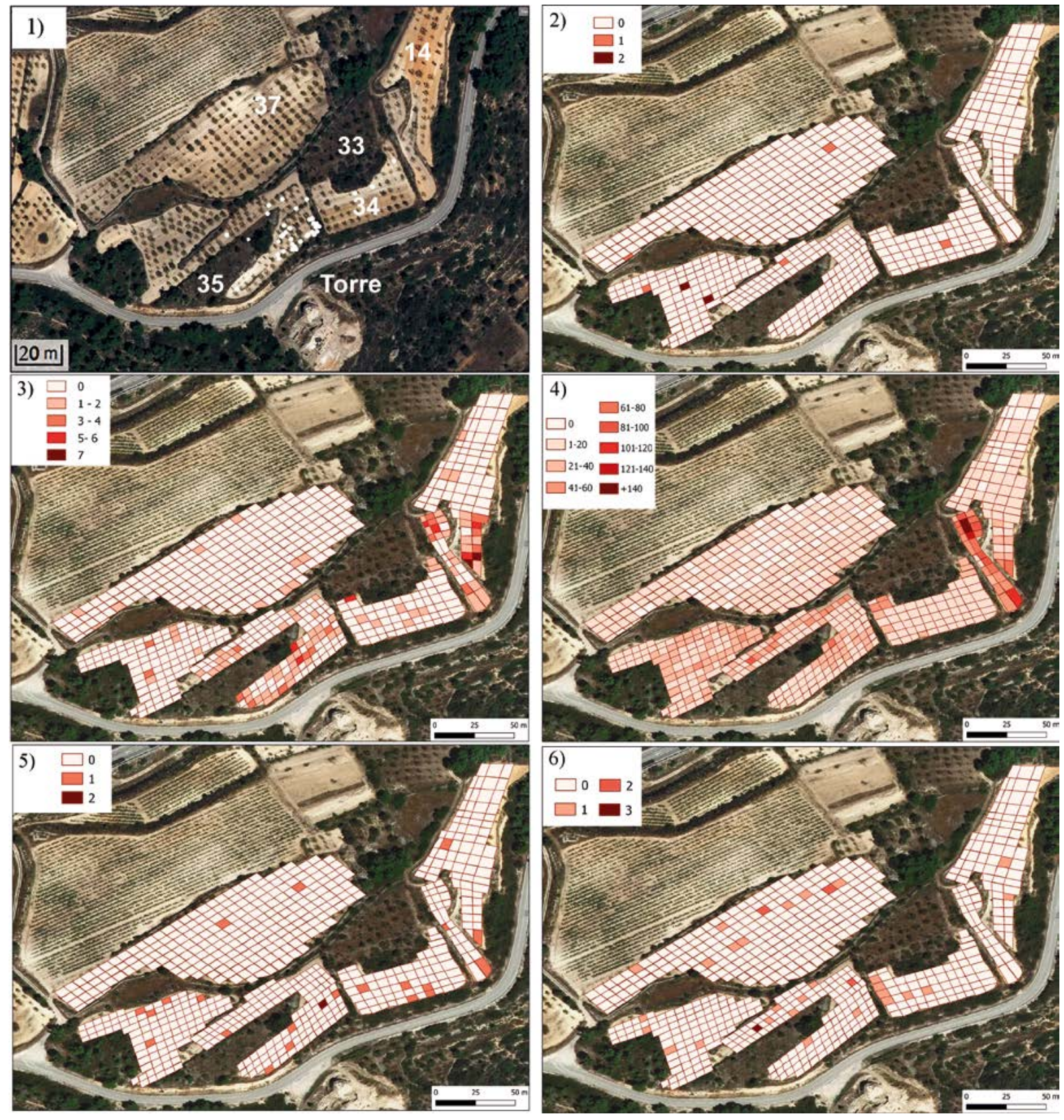

Fig. 7. Parcelas prospectadas en la cima del Coll del Moro de Gandesa, indicando la dispersión: 1. de la escoria de hierro; 2 . de la cerámica fenicia; 3 . de la cerámica a mano; 4 . de la cerámica ibérica a torno; 5 . de la cerámica de barniz negro; 6 . del ánfora greco-itálica o itálica (en color en la versión electrónica)

En resumen, la prospección pedestre ha precisado la entidad, cronología y, en algún aspecto, la naturaleza de la ocupación en el Coll del Moro. La heterogeneidad de los materiales indica que era una zona de hábitat, aunque existieron espacios destinados a producciones especializadas. La densidad media del material cerámi- co se aproxima a los 0,5 fragmentos por $\mathrm{m}^{2}$, cifra semejante a la de otros núcleos urbanos protohistóricos del noreste de la península ibérica. Por ejemplo, dentro del mismo proyecto, la prospección en Masies de Sant Miquel (Banyeres del Penedès, Tarragona) ofrece una densidad de 0,6 fragmentos por $\mathrm{m}^{2}$. 
La prospección geofísica cubrió un total de 4378 $\mathrm{m}^{2}$ en las parcelas 14,34 y 35 , mediante georradar equipado con 5 antenas de $600 \mathrm{MHz}$ en lectura simultánea, siguiendo el sistema IDS RIS -MOD. Los datos se recuperaron con una resolución de $0,02 \times 0,20 \mathrm{~m}$, es decir, obteniendo perfiles hasta $1,66 \mathrm{~m}$ de profundidad, separados entre sí $20 \mathrm{~cm}$, con una lectura cada $2 \mathrm{~cm}$ sobre toda la superficie explorada. Apenas se detectaron anomalías relacionables con restos constructivos. En unos casos, sobre todo en la parcela 35, la roca natural estaba a escasos centímetros de la superficie, mientras que en otros el intenso laboreo agrícola ha destruido los muros, quizá por completo. Tan solo al sur de la parcela 34 y en un extremo de la 14, correspondiente a la zona con mayor densidad cerámica y con manchas cenicientas, se identificaron recintos. Asimismo, en el extremo sureste de la parcela 35 se detectaron tres zonas de combustión, coincidentes con las escorias de fundición ya mencionadas, lo que confirma la presencia de hornos metalúrgicos.

\section{LA PROSPECCIÓN DEL TERRITORIO}

En 2018 se realizaron prospecciones a pie en el valle de Bot-Gandesa, que se extiende al sur y sureste del conjunto arqueológico, empleando la metodología descrita para la prospección pedestre de la cima de la collada. Se centraron en La Cendrosa, una de las explanadas situadas, en diferentes terrazas, entre la sierra del Camp Teuler y el barranco de Redó (Fig. 1B). A ella se añadió la prospección intensiva de la zona de Lo Grau, a unos $2 \mathrm{~km}$ al este del Coll del Moro, a ambos lados de la carretera N-420. En La Cendrosa se prospectó de forma intensiva una superficie de 140 ha (254 parcelas, que se utilizaron como unidades de prospección). Prácticamente todas tenían materiales antiguos, lo que apunta a una intensa presencia humana y explotación del territorio durante la segunda mitad del I milenio a. C. Sin embargo, la densidad varía de 0,03 fragmentos por $\mathrm{m}^{2}$ en la parcela 148 a tan solo 0,00008 por $\mathrm{m}^{2}$ en la 84. Ello sugiere que hay asentamientos permanentes de mayor entidad, instalaciones agrícolas de menor importancia (en torno a 0,003 fragmentos por $\mathrm{m}^{2}$ ) $\mathrm{y}$, en las parcelas con densidad de materiales inferior al 0,003 , que la propia explotación agrícola causó su dispersión, tal vez acompañando al estiércol en el abonado de los campos (Snodgrass 2002: 188-189). Este paisaje formado por granjas o caseríos de reducidas dimensiones, situados en pequeñas elevaciones, coincide con el sistema documentado en el interfluvio Algars-Matarraña (Moret et al. 2006).

Una de las zonas de mayor densidad $(0,02$ fragmentos por $\mathrm{m}^{2}$ ) y extensión (unas $2 \mathrm{ha}$ ) se encuentra en el piedemonte del Coll del Moro (Fig. 1B, $n^{\circ} 2$ ), a una cota de $80 \mathrm{~m}$ por debajo del mismo. Los materiales, fechados entre los siglos VII y III/II a. C., cubren un radio de $400 \mathrm{~m}$ desde el núcleo ibérico. Una parte del material recogido puede proceder del asentamiento situado sobre la collada, sin excluir que hubiera otro en esta zona.

Otras dos áreas de particular densidad están sobre sendas elevaciones de unos $350 \mathrm{~m}$ s. n. m., a 1300 y $1400 \mathrm{~m}$ respectivamente del Coll del Moro, en dirección sureste. La primera (Fig. 1B, $n^{\circ} 3$ ) es de la Edad del Hierro, con materiales fechables entre el siglo VII y el siglo III a. C. La segunda (Fig. 1B, no 4) se fecha entre el Primer Hierro y el Alto Imperio (siglo VII a. C. - siglo II d. C.). En la primera existe una alineación de recortes circulares en la roca, posibles hoyos de poste.

La prospección de lo Grau documentó una posible necrópolis y dos yacimientos de carácter agrícola. La primera se deduce del hallazgo de elementos de bronce propios del Ibérico Antiguo (hebilla de cinturón, colgantes con apéndice esferoidal y zoomorfos). En uno de los asentamientos rurales las cerámicas se dispersan por unos $2.000 \mathrm{~m}^{2}$. La mayoría son vasos de transporte y almacenaje. También hay un molino rotatorio. El material de importación (Lamb. 27 de campaniense $\mathrm{A}$, Lamb. 5 de campaniense $\mathrm{B}$, ánfora itálica indeterminada) y dos monedas de las cecas de Bolskan y Tamaniu permiten datarlo en torno 100 a. C. (Fig. $1 \mathrm{~B}, \mathrm{n}^{\circ}$ 5). El segundo ocupa una superficie de unos $2.300 \mathrm{~m}^{2}$. Aquí abunda la vajilla romana fechable entre finales del siglo I a. C. y finales del siglo II d. C., acompañada de tejas y fragmentos marmóreos de decoración arquitectónica. Se trata probablemente de la pars urbana de una villa (Fig. $1 \mathrm{~B}, \mathrm{n}^{\circ} 6$ ).

\section{EL COLL DEL MORO EN SU CONTEXTO MICROREGIONAL (FIG. 1A)}

El Coll del Moro es el hábitat de mayores dimensiones en un territorio con el límite occidental situado en la sierra de Cavalls ( 707 m s. n. m), en cuya parte superior hay pequeños enclaves, a modo de atalaya, entre los barrancos que comunican con el Ebro. Desde ellos se divisa toda la hoya de Bot-Gandesa y el altiplano septentrional de la Terra Alta, e incluso el valle medio de los ríos Algars y Matarraña por el este y las tierras bañadas por el Ebro a su paso por Móra al oeste.

Los límites occidentales del territorio controlado por el Coll del Moro pueden situarse en el macizo de les Roques de Benet, la montaña de Santa Bàrbara y la sierra dels Pesells. En sus laderas existe una serie de yacimientos de unos $1.000 \mathrm{~m}^{2}$ (Puch 1996: 51). Una hipótesis alternativa los sitúa en el río Algars, donde

Trab. Prehist., 77, N. ${ }^{\circ}$ 1, enero-junio 2020, pp. 113-129, ISSN: 0082-5638

https://doi.org/10.3989/tp.2020.12249 
hay un sistema de yacimientos sobre los cerros y colinas que dominan las terrazas fluviales y controlan los pasos hacia el este (Jornet 2017: 256).

Los límites norte y este del territorio del Coll del Moro son más difíciles de determinar por la ausencia de accidentes geográficos notables. Por el norte se abre un extenso altiplano hasta el Ebro, con algunos yacimientos de menor entidad sobre un radio de unos 10 km, como los de Coll del Moro del Borrasquer y Coll del Moro del Xollat. Hacia el este los escasos indicios de poblamiento se sitúan cerca del camino que enlaza la Terra Alta con el Ebro, siguiendo el cauce del barranco de la Font de l'Aubà y el río Sec, y no más allá, hacia el este, de Les Camposines. Ello podría atribuirse a su condición de área fronteriza, poco poblada hasta, por lo menos, la fundación del Castellet de Banyoles (Sanmartí et al. 2012: 59).

\section{DISCUSIÓN Y CONCLUSIONES}

Las intervenciones realizadas desde 2014 permiten reinterpretar la superficie total y evolución estructural del hábitat del Coll del Moro de Gandesa, con importantes consecuencias sobre el proceso histórico de la sociedad ibérica de la zona del curso inferior del Ebro. Los hallazgos de ánfora fenicia arcaica y otras afines, aunque descontextualizados, confirman una ocupación desde el siglo VII a. C., extendida a los campos situados al pie del yacimiento. La naturaleza de este primer núcleo es desconocida, pero la collada del Coll del Moro es el paso natural entre las comarcas de la Terra Alta y el Matarraña. Ello abre la posibilidad de que existiera un centro de recepción y redistribución hacia el interior de las ánforas fenicias llegadas por la vía del Ebro, tal vez del tipo de Aldovesta (Mascort et al. 1991), aunque el número de envases fenicios conocidos en el Bajo Aragón es muy reducido (Fatás 2016: 227).

La construcción de la torre y la excavación de la balsa pueden remontar también a finales del Primer Hierro o principios del período ibérico. Se relacionan con el control de un territorio amplio y con la circulación de ganado, que justificaría la instalación del gran depósito de agua. Hay otros similares, aunque de dimensiones mucho menores, en asentamientos de cronología semejante, como Barranc de Gàfols (Sanmartí et al. 2000: 96-100) y, en el Bajo Aragón, Záforas (Pellicer 1959: fig. 2) y Cabezo de Monleón (Beltrán 1980: 54-55), fechados en el siglo VII a. C. Más recientes son los de San Antonio de Calaceite (Bosch Gimpera 1932: 77), Palermo I (Caspe, Zaragoza) (Melguizo 2011) y el Palao (Alcañiz), este último de época ibero-romana (Marco 2003). Esta interpretación es coherente con la presencia de las dos balsas de crono- logía indeterminada situadas junto a un antiguo camino ganadero en la parte superior del Coll del Moro.

La rápida colmatación de las cisternas, aquí y, en especial, en Barranc de Gàfols, permite suponer cambios importantes de la estructura económica, coincidiendo con el desarrollo inicial de la cultura ibérica y la formación de sociedades profundamente jerarquizadas y desiguales. En el Coll del Moro la drástica reducción del número de tumbas durante los siglos VI-V a. C. (Rafel 1989: 39 y 81-84; Rafel 1991: 140-141) puede explicarse por la restricción del ritual funerario al estrato superior, muy reducido, de la población, lo que a su vez remite a la implantación de una ideología legitimadora de la desigualdad (Sanmartí et al. 2015). Un papel importante en el desarrollo de este proceso de cambio debió de jugar el crecimiento de la población, favorecedor de la economía agrícola a costa de estrategias como la caza, la recolección forestal (ambas atestiguadas todavía en Barranc de Gàfols) (Sanmartí et al. 2000: 180; Albizuri y Nadal 2000: 197; Cubero 2000) y la ganadería. Las dimensiones en torno a 3 ha que alcanzó el hábitat sobre la collada y la intensa explotación del territorio documentada en el llano de Bot son coherentes con esta hipótesis. La metalurgia del hierro debió de desempeñar un papel fundamental (todavía mal documentado) en esta dinámica de cambio. Recordemos que, en la cima de la collada, había una zona de probable producción siderúrgica, cuya naturaleza y cronología se investigarán próximamente.

En el período Ibérico Pleno, en especial en el siglo III a. C., el Coll de Moro es mucho más que un punto de observación y de control de las comunicaciones. Esta pudo ser su función primordial en el Primer Hierro y el Ibérico Antiguo, pero, dada su extensión y la importancia de su ocupación, a juzgar por la densidad de hallazgos de material mueble, cabe afirmar que el asentamiento adquirió, tal vez a partir del siglo IV a. C., una entidad mucho mayor, quizá de carácter urbano. Milita en este sentido su control sobre la organización y explotación de un territorio de más de $200 \mathrm{~km}^{2}$. En consecuencia, debió de incluir una población social y económicamente diversa: un núcleo aristocrático, artesanos del sector metalúrgico $\mathrm{y}$-dadas las dimensiones del asentamiento- una población campesina importante, en parte dedicada a la producción vitivinícola y de lino (Belarte et al. 2019). San Antonio de Calaceite (Sanmartí-Grego 1984; Jornet 2017), uno de sus homólogos durante el Ibérico Pleno, debió de ejercer funciones similares en el vecino territorio de la comarca del Matarraña, y lo mismo puede decirse del Palao de Alcañiz (Benavente et al. 2003). Sin embargo, la ausencia de datos sobre la estructura interna del Coll del Moro impone una cierta prudencia a la hora de calificarlo como urbano.

La torre estuvo ocupada de forma continuada hasta el abandono del lugar. Sin embargo, desconocemos 
cómo se configuraba, antes del siglo III a. C., el asentamiento en la zona al sur-sureste de la cisterna y de la torre, e incluso si estaba ocupada o era un amplio espacio abierto. Esto último es posible, ya que en la excavación no aparecieron construcciones previas a las del siglo III a. C., probablemente ya muy avanzado, cuando se aisló el espolón triangular donde se alza la torre. Ello supuso su segregación radical del hábitat que se extendía por la parte superior de la collada, al norte de la carretera actual. La profunda significación sociológica de este cambio en la estructura espacial del asentamiento queda confirmada por la mansión aristocrática que se elevó en la zona segregada. La mansión debió de mantener una conexión simbólica con la gran torre, que venía materializando la permanencia y continuidad del poder desde el Ibérico Antiguo. Esta interpretación es congruente con la situación de las construcciones en un espolón aislado, visible a gran distancia desde el sur, este y oeste, y, desde luego, con la naturaleza estratificada de la sociedad ibérica y el control atribuible a la aristocracia sobre producciones de prestigio, como los tejidos (al menos algunos de ellos) y el vino. Discrepa de esta interpretación el reducido volumen de las importaciones en el edificio B (el $1 \%$ ), excavado por nosotros (no hay cuantificaciones para el resto). Ello puede deberse a su finalidad productiva y de almacenaje, no residencial.

El trasfondo de esta configuración de la sociedad ibérica local es la coyuntura política regional del último tercio del siglo III a. C. La naturaleza fortificada de la mansión aristocrática, el aislamiento del espolón donde se eleva y los aditamentos al sistema defensivo (nueva cisterna, probable adecuación de la torre, reducción del espacio de acceso al interior del edificio fortificado) no puede desligarse de la intervención cartaginesa en Hispania y de sus consecuencias, que culminaron con la conquista del territorio por Roma. Esta última podría explicar la destrucción violenta de la parte excavada del yacimiento en torno a 200 a. C. y las pocas importaciones del siglo II a. C. en el resto del mismo, sobre la collada. La virulencia de su impacto supuso la decapitación de las estructuras de poder de las sociedades indígenas. Pese a ello, el gran edificio del siglo III a. C. fue ocupado de nuevo, de manera efímera y al menos en parte con usos similares, en la segunda mitad del siglo II a. C.

Finalmente, el conjunto constructivo romano-republicano recuerda a un tipo de edificio distinto, típico de este período, con técnicas constructivas y ornamentales esencialmente itálicas; en algún caso, su refinamiento sugiere su ocupación por personajes de un cierto estatus social. Se interpretan generalmente como núcleos fortificados que ejercían el control sobre un territorio sometido, pero aún no transformado a través de la fundación de las nuevas ciudades romanas y la colonización agrícola. Su cronología se sitúa a partir de mediados o el tercer cuarto del siglo II a. C. hasta principios del siglo I a. C. A partir de entonces las nuevas estrategias de Roma comportan su abandono o su transformación. El edificio del Coll del Moro, por su ubicación en un punto de gran valor para el control del territorio y por la estructura de los restos conocidos, se inscribe en este tipo, pero con la lógica peculiaridad de haber incorporado la antigua torre ibérica. La articulación de las construcciones en torno a una gran torre también ocurre en la vecina Torre Cremada, en la Vall-del-Tormo, que controlaría visualmente buena parte de la cuenca del Matarraña (Moret et al. 2006: 127). Ambos insinúan un modelo regional de fortificación empleado para asegurar el control y garantizar la explotación del territorio. Esta ocupación romanorepublicana parece reducirse a esta zona del yacimiento. A diferencia de, p. ej., en Burriac (Ilturo), la antigua ciudad ibérica no resurgió, como tampoco lo hiciera San Antonio de Calaceite ni probablemente el Castellet de Banyoles (Sanmartí et al. 2012: 51-52). El edificio romano-republicano se abandona en algún momento del siglo I a. C. Después, el Coll del Moro es un punto de observación de mínima entidad constructiva. Todo ello será objeto de investigación y análisis en los próximos trabajos de prospección y excavación.

\section{BIBLIOGRAFÍA}

Albizuri, S. y Nadal, J. 2000: “Anexo 1. Estudi arqueozoològic de les restes faunístiques recuperades al jaciment del Barranc de Gàfols (Ginestar, Ribera, Ebre)". En J. Sanmartí, M. C. Belarte, J. Santacana, D. Asensio y J. Noguera: L'assentament del bronze final $i$ la primera edat del ferro del Barranc de Gàfols (Ginestar, Ribera d'Ebre). Arqueo Mediterrània 5, Universidad de Barcelona. Barcelona: 197-207.

Alonso, N. y Juan, J. 1994: “Anexo. Fibras de lino en las piletas del poblado ibérico del Coll del Moro (Gandesa, Terra Alta): estudio arqueobotánico". Trabajos de Prehistoria 51 (2): 137-142. https://doi.org/10.3989/tp.1994.v51.i2.452

Asensio, D.; Cardona, R.; Morer, J.; Pou, J.; Gil, B.; Cantero, F. J. y Ferrer, C. 2012: "El poblament ibèric al Solsonès: un estat de la qüestió a partir dels treballs del Centre d'Estudis Lacetans". Actes de les I Jornades d'Arqueologia de la Catalunya Central (Manresa 2010): 73-82. Manresa.

Belarte, M. C.; Noguera, J. 2007: La necròpolis protohistòrica de Santa Madrona (Riba-roja d'Ebre, Ribera d'Ebre). Hic et Nunc 2, Institut Català d'Arqueologia Clàssica. Tarragona.

Belarte, M. C., Noguera, J., Plana-Mallart, J. y Sanmartí, J. 2019: “On the notion of the city and its relevance for the study of the western Mediterranean Protohistory". En M. C. Belarte, J. Noguera, R. Plana y J. Sanmartí (eds.): Urbanization in Iberia and Mediterranean Gaul in the first millennium BC. Treballs d'Arqueologia de la Mediterrània Antiga (TRAMA), 7, Institut Català d'Arqueologia Clàssica. Tarragona: 11-18.

Beltrán, A. 1980: Cabezo de Monleón. Atlas Arqueológico de Aragón. Zaragoza.

Benavente, J. A.; Marco, F. y Moret, P. 2003: "El Palao de Alcañiz y el Bajo Aragón durante los ss. II y I a. C.”. Archivo Español de Arqueología 76: 231-246. https://doi.org/10.3989/aespa.2003.v76.116 
Berges, M. y Ferrer, M. 1976: “«Torre ibérica» del Coll del Moro. Gandesa (Tarragona)". Noticiario Arqueológico Hispánico, Prehistoria 5: 393-398.

Blasco, M. y Rafel, N. 1995: "El taller tèxtil de Coll del Moro de Gandesa (Terra Alta)". Tribuna d'Arqueologia 1993-1994: 37-50.

Bosch Gimpera, P. 1932: Etnologia de la Península Ibèrica. Barcelona. Ed. Alpha.

Burillo, F. 1991: "Introducción a las fortificaciones de época ibérica en la margen derecha del valle medio del Ebro". Fortificacions. La problemática de l'ibèric ple (segles IV-III a. de C.). Simposi Internacional d'Arqueologia Ibèrica (Manresa, 6-9 desembre del: 37-53). Manresa.

Casas, J.; Nolla, J. M.; Palahí, L.; Vivó, D. y Soler, V. 2016: “Mas Gusó: un establecimiento militar de época romana en el suburbium ampuritano". Archivo Español de Arqueología 89: 117-132. https://doi.org/10.3989/aespa.089.016.006

Crespo, L.; Subirà, M. E. y Ruiz, J. 2011: "Twins in Prehistory: the case from Olèrdola (Barcelona, Spain; s. IV-II BC)". International Journal of Osteoarchaeology 21: 751-756. https://doi.org/10.1002/oa.1169

Cubero, C. 2000: "Anexo 1. Estudi de les restes paleocarpològiques". En J. Sanmartí, M. C. Belarte, J. Santacana, D. Asensio y J. Noguera: L'assentament del bronze final $i$ la primera edat del ferro del Barranc de Gàfols (Ginestar, Ribera d'Ebre). Arqueo Mediterrània 5, Universidad de Barcelona. Barcelona: 209-217.

Fatás, L. 2016: "La Edad del Hierro en el valle del Matarraña (Teruel): las investigaciones del Institut d'Estudis Catalans en el Bajo Aragón”. Caesaraugusta 85: 9-462.

Ferrer, M. 1982: "Necròpolis del Coll del Moro, Gandesa". Les excavacions arqueolòiques a Catalunya en els darrers anys, Excavacions Arqueologiques a Catalunya 1, Generalitat de Catalunya. Barcelona: 238-241.

Ferrer, M. 1986: "Un sepulcre singular a la necròpolis del Coll del Moro (Gandesa, Tarragona). Observacions sobre el paisatge i les pràctiques funeràries". Empúries 48-50: 312-323.

Jornet, R. 2017: El jaciment de Sant Antoni de Calaceit $i$ el poblament ibèric de les comarques del Matarranya i la Terra Alta. Monografies del Museu d'Arqueologia de Catalunya-Barcelona 15. Barcelona.

Jornet, R.; Belarte, M. C.; Sanmartí, J.; Asensio, D. y Morer, J. 2016: "Noves excavacions al nucli fortificat del Coll del Moro de Gandesa", I Jornades d'Arqueologia de les Terres de l'Ebre (Tortosa 2016): 342-356. Tortosa.

Marco, F. 2003: "El Poblado íbero-romano de El Palao (Alcañiz): La Cisterna". Al-Qannis. Boletín del Taller de Arqueología de Alcañiz 10.

Mascort, M. T.; Sanmartí, J. y Santacana, J. 1991: El jaciment protohistòric d'Aldovesta (Benifallet) $i$ el comerç fenici arcaic a la Catalunya meridional. Publicacions de la Diputació de Tarragona. Tarragona.

Mata, C.; Moreno, A.; Pérez Jordà, G.; Quixal, D. y Vives-Ferrándiz, J. 2007: "Casas y cosas del campo: hábitat agrícola y estructura social en los territorios de Edeta y Kelin (siglos V-III a.n.e.). En M. C. Belarte (ed.): L'espai domèstic i l'organització de la societat ibèrica: els territoris de la franja mediterrània. Arqueo Mediterrània 11, Universidad de Barcelona. Barcelona: 143-152.

Melguizo, S. 2011: "Palermo I (Caspe, Zaragoza). Estilos regionales defensivos entre los siglos III y I a. C.: paralelos con San Antonio de Calaceite". Revista d'Arqueologia de Ponent 21: 199-210.

Molas, D.; Rafel, N. y Puig, F. 1986: "La necròpolis tumular del Coll del Moro, sector Maries. Campanya 1984 (Gandesa, Terra Alta)". Tribuna d'Arqueologia 1985-1986: 43-52.

Molas, D.; Rafel, N. y Puig, F. 1987a: "Orientalisierende Funde von der Grabung 1984 in der Nekropole des Coll del Moro de Gandesa (prov. Tarragona)". Madrider Mitteilungen 28: 51-57.

Molas, D.; Rafel, N. y Puig, F. 1987b: "Necròpoli del Coll del Moro (Gandesa, Terra Alta). Campanya de 1984 al sector Maries". Butlletí de la Reial Societat Arqueolòica Tarraconense V, 4-5: 21-71.

Moret, P.; Benavente, J. A. y Gorgues, A. 2006: "Iberos del Matarraña: investigaciones arqueológicas en Valdeltormo, Calaceite, Cretas y $\mathrm{La}$ Fresneda (Teruel)". Al-Qannis. Boletín del Taller de Arqueología de Alcañiz 11.
Pellicer, M. 1959: "Zaforas, nuevo yacimiento con ceràmica excisa en Caspe". V Congreso Nacional de Arqueología (Zaragoza 1957): 138156. Zaragoza.

Pera, J.; Carreras, C.; Romaní, N.; Rodrigo, E.; Padrós, N. y de Solà, G. 2016: "El proceso de implantación territorial romana en el NE de la Provincia Citerior en el siglo II a. C. Análisis de tres modelos de ocupación: Ilturo, Can Tacó y Puig Castellar de Biosca”. En J. Pera y J. Vidal (eds.): Fortificaciones y Control del Territorio en la Hispania Republicana. Ed. Pórtico. Zaragoza: 167-205.

Pérez Jordà, G. 2000: "La conservación y transformación de los productos agrícolas en el Mundo Ibérico". En Ibers. Agricultors, artesans $i$ comerciants. III Reunió sobre Economia en el Món Ibèric, Saguntum, extra 3: 139-145.

Puch, E. 1996: El poblament ibèric i romà a la Terra Alta. Centre d'Estudis de la Terra Alta. Gandesa.

Rafel, N. 1989: La necròpolis del Coll del Moro de Gandesa. Les estructures funeràries. Col·lecció Monografies. Publicacions de la Diputació de Tarragona. Tarragona.

Rafel, N. 1991: La necròpolis del Coll del Moro de Gandesa. Els materials. Publicacions de la Diputació de Tarragona. Tarragona.

Rafel, N. 1993: Necròpolis del Coll del Moro. Gandesa, Terra Alta. Campanyes 1984 a 1987. Excavacions Arqueològiques a Catalunya 12, Generalitat de Catalunya. Barcelona.

Rafel, N. y Blasco, M. 1991: "El recinte fortificat del Coll del Moro de Gandesa". Fortificacions. La problemática de l'ibèric ple (segles IV-III a. C.) Simposi Internacional d'Arqueologia Ibèrica (Manresa, 6-9 desembre del 1990): 293-301. Manresa.

Rafel, N. y Blasco, M. 1994: El Coll del Moro. Un recinte ibèric fortificat. Campanyes 1982-1983. Memòries d'Intervencions Arqueològiques a Catalunya 8 , Generalitat de Catalunya. Barcelona.

Rafel, N., Blasco, M. y Sales, J. 1994: "Un taller ibérico de tratamiento del lino en el Coll del Moro de Gandesa (Tarragona)". Trabajos de Prehistoria 51 (2): 121-142. https://doi.org/10.3989/tp.1994.v51.i2.451

Rafel, N.; Garcia-Rubert, D. y Jornet, R. 2015: Nuevos datos sobre el poblamiento en la Cataluña meridional entre el siglo VII ane y época romana: el Coll del Moro de Gandesa. Opúsculo Arqueológico 9. Teruel.

Rafel, N. y Hernández, G. 1992: "Pràctiques funeràries a la necròpolis del Coll del Moro (Gandesa, Terra Alta)". Revista d'Arqueologia de Ponent 2: 37-57.

Rafel, N.; Jornet, R. y Burillo-Cuadrado, P. 2018: "Una vasija decorada ibérica de función ceremonial: un espacio singular en el Coll del Moro (Gandesa, Tarragona)". Complutum 29 (1): 135-150. https://doi.org/10.5209/cmpl.62399

Sanmartí, J.; Asensio, D.; Jornet, R. y Miró, M. 2012: "El Castellet de Banyoles (Tivissa): Una ciudad ibérica en el curso inferior del río Ebro". Archivo Español de Arqueología 85: 43-63.

https://doi.org/10.3989/aespa.085.012.003

Sanmartí, J.; Belarte, M. C.; Santacana, J.; Asensio, D. y Noguera, J. 2000: L'assentament del bronze final i la primera edat del ferro del Barranc de Gàfols (Ginestar, Ribera d'Ebre). Arqueo Mediterrània 5, Universidad de Barcelona. Barcelona.

Sanmartí, J.; Plana-Mallart, R. y Martín, A. 2015: "Les estructures socials en els estats ibèrics de la costa de Catalunya". En M. C. Belarte, D. Garcia y J. Sanmartí (eds.): Les estructures socials a la Gàl-lia $i$ a Ibèria. Homenatge a Aurora Martin i Enriqueta Pons, Actes de la VIIa Reunió International d'Arqueologia de Calafell. Arqueo Mediterrània 14, Barcelona: 119-136.

Sanmartí-Grego, E. 1984: "Observaciones acerca del poblado ibérico de San Antonio de Calaceite en relación a su funcionalidad rectora en el poblamiento de su área de influencia”. Arqueología Espacial 4: 161-171.

Snodgrass, A. 2002: "A Paradigm Shift in Classical Archaeology?". Cambridge Archaeological Journal 12 (2): 179-194. https://doi.org/10.3366/edinburgh/9780748623334.003.0004

Vilaseca, S. 1954: Nuevos yacimientos tarraconenses de cerámica acanalada. Instituto de Estudios Tarraconenses Ramon Berenguer IV, Reus. 